\title{
Examining Gender Safety in Schools: Teacher Agency and Resistance in Two Primary Schools in Kirinyaga, Kenya
}

\author{
Catherine Vanner ${ }^{\mathbb{D}}$ \\ Department of Integrated Studies in Education (DISE), McGill University, Montreal, QC H3A 0G4, Canada; \\ catherine.vanner@mcgill.ca
}

Received: 28 October 2018; Accepted: 14 March 2019; Published: 21 March 2019

\begin{abstract}
This article introduces Stein, Tolman, Porche, and Spencer's concept of gender safety in schools (GSS) as a useful framework for providing a gendered analysis of safety and equality at the school level within the global context of the Sustainable Development Goal (SDG) 4 goal of equitable, inclusive and quality education for all. This article examines practices that support as well as undermine GSS in two primary schools in Kirinyaga County, Kenya. In these schools, individual teacher agency was the main factor enhancing GSS. Teachers' efforts were, however, constrained by competing discourses emphasizing hierarchical administration and a narrow understanding of the school's responsibilities. Teacher agency, therefore, was insufficient to systematically protect students and foster gender equity. The article suggests that teacher agency to enhance GSS in Kenya could be expanded through teachers' collective empowerment using community-based networks alongside the integration of monitoring and evaluation processes in existing gender equality and child protection policies. It further recommends the GSS framework as a means for monitoring SDG 4's commitments to gender equality and child protection in schools.
\end{abstract}

Keywords: child protection; gender equality; gender safety; gender violence; Kirinyaga County; Kenya; primary education; teacher agency

\section{Introduction}

The 2015 United Nations Sustainable Development Goals (SDGs) reflect an international consensus regarding objectives for ensuring peace and prosperity for people and the planet. The education-related goal, SDG 4, is to "ensure inclusive and equitable quality education and promote lifelong learning opportunities for all" [1]. The result of extensive global consultation [2], this goal is significantly more comprehensive than the education-related Millennium Development Goal (MDG) 2 that preceded it, which was to achieve universal primary education by 2015. A notable criticism levied against MDG 2 was that it implicitly assumed that all primary education was undifferentiated, and thereby downplayed the key factor of quality and the ways that educational experiences affect children who are themselves differentiated by gender and social status [3]. In sharp contrast, SDG 4 incorporates the notions of inclusiveness and equity, providing significant space to consider the gendered nature of school experiences. In recent years, there has been a growing recognition of the gendered dimensions of violence in schools, and its detrimental impact on the quality of education and children's learning [4-6]. Accordingly, the issue of gender safety is an important pre-condition of both equality in education and the efficacy of teaching and learning.

While there is increasing knowledge surrounding the nature of gender violence in schools (GVS) and the importance of safe learning environments for good quality education, a clear understanding of what a gender safe school would look like has not been widely taken up. For education to contribute 
to the transformation of gender inequality, a gendered analysis of school space is critical, as many gender preconceptions are learned in school. As Stromquist writes, for gender norms to be transformed through education, it is necessary to "revise conventional values and messages in the curriculum and to alter the practices of teachers, principals and students at the school site, where they constantly reproduce gendered expectations. The lived experience of schooling is an important arena for the production of gender identities" [7] (p. 148). Education's potential to act as a mechanism that will be transformative of norms contributing to gender violence, and gender inequality more broadly, relate to its prioritization of gender safety at the school level. A school that institutionalizes gender discrimination through unequal opportunities is unlikely to enable students to eventually engage in social change for equality and non-violence.

This article draws on Stein, Tolman, Porche, and Spencer's framework of gender safety in schools (GSS) to analyze elements that contribute to gender equality and child protection at the school level [8]. Instead of seeking solely to identify acts and structures of GVS and consider how to eliminate them, the framework starts with the premise that it is also important to understand how the school environment is characterized by actors contributing to gender safety, and how these actions can be supported and expanded. In using the framework to analyze two case study schools in Kirinyaga County, Kenya, this study explains how teacher agency in these schools served as a critical entry point for improving GSS even though it was at the same time being constrained by systemic barriers. Over a seven-month period of research fieldwork, data collection consisted of three months of participant observation, semi-structured interviews with teachers, and open-ended interviews with students focusing on their drawings depicting life in their schools. Teachers were observed attempting to enhance gender equality and child protection which helped to improve educational experiences for primary school students, particularly girls. Yet, as was also observed, the teachers' efforts in this regard were limited due to administrative systems that did not prioritize gender equality and child protection. As this study revealed, by highlighting such school-level narratives within a GSS framework, government and non-government stakeholders invested in reducing GVS can better understand the type of support that teachers need to be effective in enhancing inclusive and equitable quality education in line with SDG 4.

\section{Gender Safety in Schools}

Recognizing processes that promote GSS helps one to understand context-specific school practices and envision strategic solutions for eliminating GVS that build upon existing education systems. According to Stein, Tolman, Porche, and Spencer, a gender safe school is a place where girls and boys:

... have freedom to learn, explore and develop skills in all academic and extracurricular offerings to be psychologically, socially and physically safe from threats, harassment or harm in all parts of the school ... [and to acknowledge] how conventional beliefs about masculinity and femininity constrain and undermine learning, participation and movement. [1] (pp. 41-42)

This definition can be broken down into four main components: (1) absence of all forms of gender violence; (2) prioritization of gender equality in academic and extra-curricular opportunities; (3) recognition of the existence of harmful gender norms; and (4) active challenging of oppressive gender practices and expectations. The framework considers the ways that gender norms can operate in the school space both to enable gender violence but also to prevent and undermine it. A gender safe school encompasses not only the protection of children on school premises but the infusion of gender equality into pedagogical practices, curricula and school culture. GSS is premised upon the belief that schools are major sites of socialization of gender ideologies, and that a gender safe school should be an explicit focus of analysis, policymaking and practice as a basis for avoiding the reproduction of harmful gender ideologies while simultaneously promoting those that empower girls and boys [1]. "Gender safety is built on an acknowledgment of gender as a set of ideologies which are produced, reproduced 
and sustained within (and beyond) school classrooms and hallways" [1] (p. 36). This means that a school is not necessarily considered to be gender safe even when there is an absence of overt acts of gender violence. The absence of violence and discrimination is expanded upon in this framework through active challenges of discriminatory stereotypes that constrict girls' and boys' behaviours based on gender norms, both in and out of school. As it requires the linkages of gender violence to broader gender discrimination, gender safety must also be understood both within the broader structural context of gender equality and the position of the school as an agent of potential resistance.

Although the GSS framework was developed in relation to an American context, it reflects principles of gender-responsive education also espoused in African gender and education frameworks. For example, the Forum for African Women Educationalists (FAWE) defines a gender-responsive school as "one in which the academic, social and physical environment and its surrounding community take into account the specific needs of both girls and boys" [9] (p. 4). From this perspective, gender-responsive components of a safe school include the empowerment of teachers and students to challenge oppressive gender norms and implement standards to support and respond to the specific needs of girls and boys in relation to their academic, physical, and social environments. The concept of gender-responsive education has also been adopted by the Global Partnership for Education (GPE) and the United Nations Girls Education Initiative (UNGEI) in their guidance for using a gender-responsive approach in developing and implementing education sector plans. They advocate a two-pronged approach that includes gender-targeted efforts to address barriers faced by girls and boys, as well as gender-integrated efforts that involve identifying and responding to gender differences in all areas of an education sector plan [10]. The guidance notes the value of small-scale reports on the prevalence of school-related gender-based violence as data sources that can inform gender-responsive education sector plans and demonstrate evidence of linkages between GSS school-level analysis and broader education sector policy and programming conducted by governments and funded by external stakeholders such as the GPE. For education to be a mechanism that transforms harmful gender ideologies, a gender-responsive approach must be infused, embraced and prioritized by school administration and teachers. Gender equality and the recognition and subversion of gender violence and discrimination, both within and outside of school spaces, has to be embedded within every aspect of school culture for education to contribute to positive social transformation. From this perspective, without the consistent integration of this priority, education will continue to perpetuate norms of inequality and violence. The GSS framework provides an instrument for identifying gender positive practices, as well as the barriers that need to be overcome if a truly gender safe school is to be achieved.

\section{Educational Context in Kenya}

\subsection{Gender Violence in Schools in Kenya}

As Leach observes, schools are sites where boys and girls learn and adopt "what they see as conventional male and female behaviour. Boys may learn that the violence they witness in the wider world is acceptable within institutions ... and girls may learn to accept it" [11] (p. 389). Gender violence in schools can take multiple forms: "physical, verbal, psychological and emotional as well as sexual violence, including the fear of violence, both between females and males and among females or among males" [12] (p. 53). Not only are students susceptible to the perpetration of violence in schools as a normative demonstration of masculinity, but they may then understand it as an acceptable feature of their education, especially when they see teachers participating in, condoning, or ignoring instances of violence in schools. As Parkes observes, violence is a continuum, ranging from "extreme" forms of violence such as rape to "everyday" forms such as playground disputes [13]. Some types of gendered violence, such as sexual violence, target primarily girls and are most frequently perpetrated by male teachers and students [14]. Other forms of violence in school, notably corporal punishment, are more frequently and severely inflicted on boys [14,15]. Given its intersectionality with inequality and poverty, 
gender violence is reproduced and enabled by multiple structural and systemic practices [13]. It is therefore often structurally embedded in the normal course of peer and teacher-student interactions.

In Kenya, gender violence in schools is a legacy that dates back to the colonial era when British administrators imposed the authoritarian model of formal education that was commonplace in Britain and became prevalent in other colonies and protectorates. The prevalence of multiple types of violence perpetrated on children, both within and outside Kenyan schools, continues to be a source of major concern [16-21]. In a national survey of violence against children aged 13 to 17 years, $49 \%$ of girls and $48 \%$ of boys reported that they had experienced physical violence, and $11 \%$ of girls and $4 \%$ of boys indicated that they had experienced sexual violence [16]. The respondents likewise indicated that teachers were the most common authority figures perpetrating physical violence against children. In the same study, $20 \%$ of perpetrators of sexual violence reported by females and $35 \%$ of those reported by males were identified as friends or classmates [16]. This is consistent with other studies showing a high prevalence of sexual violence in Kenyan primary and secondary schools [7,17,19,20]. Other forms of violence, such as corporal punishment and bullying, are also widespread in Kenyan schools [21,22]. A study by Parkes et al. [18] reported that $86 \%$ of girls consulted had experienced some form of physical, psychological, or sexual violence within the previous year. That GVS has been perpetuated so widely in Kenyan schools stems in part from the strictly authoritarian nature of formal education and the corresponding use of corporal punishment for behavior management. In addition, in view of the extensive pressure that schools and teachers face to ensure that students perform well on standardized tests, high academic performance on examinations is prioritized, sometimes above other considerations such as child wellbeing, with intimidation and corporal punishment used for motivational purposes [21].

\subsection{Kenyan Policy Context}

As a signatory of the 1989 UN Convention on the Rights of the Child, the Government of Kenya formally established the imperative of child protection and school safety through a number of legislative and policy measures. The Children Act that came into effect in 2001 and was amended in 2014 prohibits the discrimination, torture, cruel treatment, sexual exploitation and physical punishment of children, and highlights children's right to protection from physical and psychological abuse, neglect, and all forms of violence [23]. Similarly, in acknowledging the risks that girls have long faced in schools, the Ministry of Education's Gender Policy in Education, announced in 2007, promotes measures to eradicate the array of factors-including sexual harassment and discrimination, gender stereotyping in learning materials and pedagogy, and negative socio-cultural practices and attitudes-that have long undermined girls' access to education and inhibited their learning [24,25]. This has been reinforced in the Ministry of Education's Safety Standards Manual for Schools in Kenya that declares school safety to be a community responsibility and requires teachers to prohibit all forms of school violence and report suspected cases of child abuse [26]. Both these policies have been endorsed by the Teacher Service Commission, which is the accreditation body for the teaching profession in Kenya. More recently, the Basic Education Act of 2013, which asserts the constitutional right of every child to free basic education, stipulates the imperative of eliminating gender discrimination and abolishing corporal punishment in schools [27].

The precepts of gender equality and school safety are therefore explicitly affirmed by the Kenyan government and by the central organs of the country's national education system. To date, however, the prevalence of corporal punishment, bullying, and sexual violence in schools reveals that these legislative and policy measures are not being effectively realized in schools. In part, this is due to the lack of operationalization plans and resources necessary to ensure that such measures are fully implemented throughout the education system. This is by no means unique to Kenya; proclamations in other countries regarding the imperative of reducing gender violence in schools have likewise been stymied by multiple obstacles and constraints [5]. As Unterhalter et al. have observed, "translating policy on gender and education into practice that enacts gender equality requires considerable resources 
in terms of money, time, skill, support and opportunities for critical reflection and communication, way beyond that planned for or provided" [28] (p. 41). In such circumstances, those who are at the frontline of education-the teachers and school principals-are invariably left to their own devices to interpret and implement the goals of gender equity and safety in their schools.

The extent to which these legislative and policy objectives were implemented in two primary schools, and their influence on students' learning processes, is the subject of this article. The two schools are located in Kirinyaga County, a rural and agricultural region [29,30]. Education indicators in Kirinyaga are generally higher than the national average, with a near universal primary school enrolment rate and functional literacy and numeracy levels that are approximately double the national average [31]. In 2013, among adult residents in Kirinyaga County, 59\% and 28\% were estimated to have completed primary school and secondary school, respectively [31]. These education indicators are higher than the national average and can be attributed to a number of factors including above-average income levels, relatively low rates of food insecurity, close proximity to the capital city of Nairobi, and the mainly Kikuyu demographic composition which is strongly represented in national political and bureaucratic positions. Despite these advantages, however, there are widespread concerns regarding the poor quality of education in the county. For example, in a national study published in 2011, approximately half of early primary school students tested in Kirinyaga could not perform the expected math and reading skills for their grade levels, and high absenteeism rates were said to be common among both students and teachers [32].

\section{The Field Study}

The two Standards 1-8 primary schools that were selected for this study, with advice from the sub-county Education Office, are referred to as the town school and the rural school (reflecting their locations). During data collection, I lived in the town school community. Data collection was divided into two phases. Phase 1 consisted of participant observation and lasted from January-April 2015, when I observed school assemblies and staff meetings, and participated in all aspects of school life. I volunteered as a means of giving back to the school communities and in order to establish a membership role in the schools [33]. Phase 2 (April-July 2015) consisted of individual interviews with students and teachers. Table 1 illustrates the number of classroom observations, and teacher and student interviews conducted. The individuals who are quoted are identified with pseudonyms.

Table 1. Methods used.

\begin{tabular}{cccc}
\hline Method & \# Female & \# Male & \# Total \\
\hline Classroom lessons observed & 30 & 22 & 52 \\
\hline Students interviewed initially & 18 & 13 & 31 \\
\hline Teachers interviewed initially & 5 & 8 & 13 \\
\hline Students interviewed-member check & 3 & 3 & 6 \\
\hline Teachers interviewed-member check & 2 & 1 & 3 \\
\hline
\end{tabular}

With the help of a research assistant, in each school I began student consultations with an introductory session with the whole class from which student participants were recruited. The schools' administration identified a Standard 8 class in the rural school and a Standard 7 class in the town school for open-ended art-based individual interviews which we conducted with the students using the Draw-Write-Narrate method [34]. This method gave the children the opportunity to draw their personal narratives in response to an open-ended question and to write a description of the drawing. The entire class participated in the drawing so as to minimize feelings of exclusion among students not recruited for participation in interviews. In this study, we posed the question: "How do you feel when you are at school?" After providing the students with examples of drawings we encouraged them to draw something they liked and something they disliked about school. 
Once they had finished drawing, we asked them to write their names on slips of paper, to indicate if they wanted to participate in an interview, and if so, to provide contact information for their parents or guardians. This provided a confidential first step in the consent process where children self-selected to participate in the interviews. Their decision was not made known to their peers or teachers. In the interviews, the students described their pictures and were asked questions to probe for greater clarity and depth. The research assistant translated all student interviews to enable students to speak in the language of their choice (Kikuyu, Kiswahili or English) and she participated in data analysis to validate the study's cultural relevance. Individual semi-structured interviews were also conducted with teachers. The sample size for student and teacher interviews was determined by a combination of factors including participant interest, time, and reasonable representation of the teacher and upper primary student population in each school. For student and teacher interview scripts, see [35].

Constructivist grounded theory was applied to develop the emergent theory, involving simultaneous data collection and analysis, continuous comparison across data sets, memo writing and recognition of the active role of the researcher in shaping the narrative [36]. I employed continuous memoing and comparisons across data sources to develop an emergent theory based on the experiences of participants. Coding consisted of three main phases: (1) initial coding which included naming each segment of data; (2) a focused, selective process to organize data based on the most frequent or significant initial codes; and (3) theoretical coding to identify possible relationships between the categories developed in the second stage [35]. Following initial interviews, member check interviews-a process by which initial analysis is validated with research participants [36] -were conducted with teachers and students. In the member check interviews, a list of emergent themes based on initial analysis was presented to the interviewees, and each was asked whether they agreed or disagreed with the themes. Follow-up questions were posed so they might contextualize and elaborate on their initial answers. The first objective of these interviews was to ensure a coherent understanding of participants' perceptions and experiences of reality [37]. The second objective was to practice theoretical sampling, which is the process of "seeking and collecting pertinent data to elaborate and refine categories in your emergent theory" [36] (p. 96), a key tenet of constructivist grounded theory analysis. The students and teachers generally affirmed the relevance of the emergent themes and provided important clarifications of some concepts and practices, giving more detail as to their importance and context.

\section{Results}

In the two case study schools, some teachers enhanced gender safety by being available for students who feared gender violence from their peers or needed support following incidents of sexual assault. In some instances, teachers actively challenged gender discrimination propagated against students by figures of authority. When they did so, however, it was on an individual basis and out of expressions of concern for the students, and not as an expected professional obligation, or in opposition to the hierarchical structure of the school system per se. Moreover, on other occasions teachers simply reinforced the status quo of inherent gender violence when using corporal punishment or by ignoring reports of sexual harassment and the Ministerial mandate to report sexual assault. Indeed, despite some acts of individual resistance and many demonstrations of support needed for students struggling with the ramifications of gender violence, teachers' ability to protect students was ultimately constrained by the hierarchical system of school authority, particularly in reference to reported cases of sexual assault.

The following section outlines teachers' roles in fostering a gender safe and equal environment for students, the constraints they faced in doing so, and the inadvertent ways in which they reproduced gender violence and discrimination. 


\subsection{Advocating for Gender Safety}

In both schools, the over-riding emphasis of activity was on curriculum-based learning and scholastic performance. This stemmed in part from communications from the Ministry of Education, and in part from the longstanding societal ethos concerning examination results as the determining factor of educational achievement. In contrast, policies emphasizing gender equality and child protection, as exemplified by the Safety Standards Manual for Schools in Kenya, with its stipulations concerning the necessity of ensuring non-violence in schools and the requirement of teachers to report cases of sexual assault to the relevant authorities, did not figure prominently in the daily discourse of either the town or the rural school. Discipline and academic success were the primary expectations of student conduct. Nevertheless, beyond their official duties in teaching the prescribed curriculum, a number of teachers did respond supportively to gender violence faced in the school and community. This was not due to a mandated code of conduct or formal administrative requirement-which existed but which they were largely unaware of-but rather followed from genuine concern for their students. Some students confirmed that their teachers enhanced their safety in both the school and community. This view was revealed in their drawings that depicted a sense of closeness between students and teachers. For example, as shown in Figure 1, the student illustrates a student and teacher learning together with the accompanying text, "Sometimes I usually feel like I can't do anything even playing but my friends always encourage me and even my teachers usually help." Figure 2 shows a teacher with two students and the accompanying text: "I am proud of my teacher." This view of relations with teachers was nonetheless selective. In the rural school, most students identified the same teacher as the one they would turn to for support because she was kind and took their concerns seriously. Gaining the confidence of students enhanced this teacher's ability to advocate for her students.

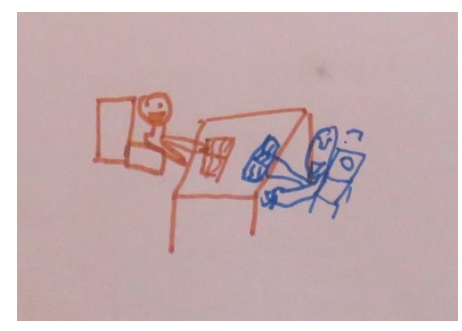

Figure 1. Teachers usually help. Student drawing.

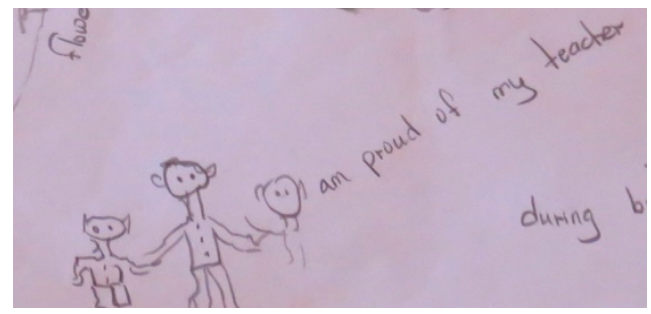

Figure 2. I am proud of my teacher. Student drawing.

Given the close proximity with their students, teachers can often detect when a child had been subject to physical harm outside of the classroom or even beyond the school grounds. On several occasions, teachers described being open to students who approached them with personal concerns, and acting to assist them if they appeared fearful and distracted by some external threat. Instances such as providing funds for students who were going hungry, reaching out to parents to discuss a child's social problems, following up on repeated school absenteeism (especially among girls), and providing emotional support for student victims of assault were actions that teachers undertook. Several teachers acknowledged to me that alongside their expected tasks of instructing children in the classroom and maintaining school order and discipline, they were concerned about the wellbeing of the students with 
whom they interacted on a day-to-day basis. An illustrative example arose in an impromptu discussion concerning the welfare of several students living in a nearby children's home, when an experienced female teacher pounded on the desk and exclaimed "We are here for the children!" Another teacher stated that she felt a responsibility in school to advocate on behalf of students who lacked the status and authority to protect themselves: "As a teacher I make sure that I'm their advocate for many years because most of these children are vulnerable ... they cannot express themselves. They cannot tell ... their rights, so they cannot speak about themselves."

On numerous occasions, when sexual assault of students was reported to the police or other state authorities, teachers went out of their way to support those who were victimized. This was demonstrated by the account of a female student in Standard 4 (the fourth year of primary school) whose "wild" behaviour followed her father's sentencing to prison after he sexually assaulted her. Several of her teachers strove to accommodate her erratic behavior and to encourage her as she clearly suffered the effects of ongoing trauma. As one teacher explained their efforts to assist the student, "We have been following, following, following until it is ended. And you'll keep on counseling that child so you can bring the child back to class and to the level where the other students are. Because the child ... always looks traumatized. So, you have to make the child very friendly to you ... We would laugh with her, talk to her. Yes, just to make her feel we want her." Another teacher offered the student small classroom responsibilities which appeared to be effective in providing an outlet for her pent-up aggression and her need for a sense of purpose and confidence. For these teachers, caring and support of vulnerable children in their classrooms were instinctual responses that emerged from their own personal sense of caring.

\subsection{Challenging Gender Inequality}

Despite the formal school discourse of gender equality in relation to academic expectations, boys in both schools remained privileged in terms of school chores and sports. While male and female students were responsible for carrying out daily chores and keeping the school clean, boys were generally given more free time in school for studies and sports. Some teachers deviated from this norm and took actions that challenged unequal treatment of girls outside of the classroom. For example, as described in this field note, a Standard 3 teacher at the rural school explained to me how she had intentionally changed her teaching practice to become more egalitarian in her assignment of school chores: "She told me that all boys and girls should do all types of chores. She said previously she ... had boys do certain tasks and girls do more cleaning, but then eventually she came to see it differently." Although she could not pinpoint what prompted this change in her views concerning gender roles in relation to manual work, the teacher had realized that she was maintaining an unequal status quo division by failing to apportion chores equally to all her male and female students regardless of gender. Only by recognizing the different social expectations for girls and boys was she then able to identify the differences in their treatment and develop a systematic process of ensuring that girls and boys were equally responsible for the cleanliness of their classroom and the school environment.

Resistance to gender inequity could also be much more overt. A teacher at the town school described an intervention she had undertaken to rectify discrimination propagated by the male deputy head teacher (DHT) at the school. The DHT, who believed a boy should be student president, had replaced the student-elected female student with the male runner-up. According to one female teacher who described this situation with some indignity, "It is because of the gender!" She later described the situation thus:

Because they voted democratically ... So the girl had the most marks or the highest points. Then after that they picked the girl to be the leader. Then they needed an assistant, so they voted for the boy... So when they talked of the girl being the junior, of course I had to fight for the girl's right. Yeah, and she's still the boss because she was democratically elected. Yeah! 
This teacher felt sufficiently empowered to challenge the discriminatory decision of the male DHT to ensure gender justice for her student. Her indignant statement, "Of course I had to fight for the girl's right," demonstrated her recognition that gender inequality can pervade the school environment and that there was a need to explicitly identify, address and rectify gender discrimination. By resisting the patriarchal expectations exhibited by the DHT, she enabled a female student to assume the position of authority that she was elected to by her peers.

\subsection{Constrained Teacher Agency}

While the agency that many teachers exhibited towards their students within school environments did contribute to some degree of safety and equality, what was equally evident was the significance of administrative endorsement for the protective support (or lack thereof) of children. As one teacher in the rural school explained, the expectations set by the school administration shaped the school environment and influenced teacher-student communication and thus teachers' ability to protect and support students. As he stated, "There is a big gap between pupils and teachers ... Many things can happen without the knowledge of the teachers. It is not like this everywhere, more in some schools than others... It is due to the administration. The gap means that there is little interaction between teachers and pupils, a clear divide ... Pupils are then less likely to come share issues with teachers." This dependency on attitudes of school leadership underscores a fundamental limitation with the Kenyan government's professed commitment to school safety and child protection. As set out in the Safety Standards for Schools in Kenya Manual and the Teacher Service Commission's (2010) circular on the protection of students from sexual abuse, teachers are legally required to uphold standards of school safety and to report any suspected sexual abuse to authorities [27,38]. In practice, however, as recounted by the teachers in both schools, when apprised of serious infringements on student safety, most saw it as their responsibility to report to the head teacher who was seen as being responsible for deciding whether the matter should be pursued within the parameters of the school, if at all, or whether it should be relayed to external authorities such as the police or the local office of Kenya's Department of Children's Services. The significance of respecting the structure of hierarchical decision-making was revealed in this interview with a teacher in the town school:

Teacher: We follow the protocol that the Head should agree on ... I can't just go and maybe start an initiative in the school. Because the Head has to agree to that ...

Researcher: So, if the Head did not agree that it was important to do something, nothing would happen?

Teacher: Ah, nothing! I can't go ahead. No. Because I am bound ... to use the protocol of the Head in the school.

While teachers may have their own personal concerns regarding children's welfare, in practical terms they tend to regard their ability to report abuse or violence against school children as being limited. Given the authoritative structure of school leadership in Kenya, despite policy guidance to the contrary, most teachers are unwilling to intervene on a child's behalf without their head teacher's consent. As one teacher stated, after reporting an incident of violence against children to her school principal, "I have done my part. I will not go outside [the school] and start reporting it to the police." An instance of such reluctance occurred during my fieldwork when a male teacher in the rural school was informed by a Standard 6 student that she was being sexually assaulted by her stepfather. The teacher reported the matter to the head teacher who declined to report the case. Concerned that he would be sanctioned if he took the matter to authorities outside the school, the teacher said he could do nothing else other than express sympathy for the girl (see [35]).

On another occasion in the town school, the head teacher described a situation that arose when a parent asked her to help her son cope with the after-effects of sexual violence that he had experienced. The head's advice to the parent was that she should report the incident to the office of the Department 
of Children's Services. The head teacher did not, however, follow up on the case with either the parent or the student as she regarded the matter as being the sole responsibility of the Department of Children's Services and not that of the school. Such examples of teachers' and school principals' responses revealed that policy requirements related to reporting of abuse were not prioritized by school administration, and that when faced with the head teacher's opposition, teachers felt unable to pursue further measures to protect their students from viable threats of gender violence.

\subsection{Reinforcing Gender Violence}

Students demonstrated their ability to distinguish between teachers who took their concerns seriously and would provide advice, and those who reproduced the threat of violence. As one Standard 7 female student explained, when facing sexual harassment from peers, "Some [teachers] will give you advice on what you should do but others will tell you to go and report to another teacher." This statement summarizes the individual and varied approaches of teachers regarding care for students and the extent to which they were prepared to intervene on behalf of children at risk of various forms of violence. Students indicated that they could not confide in some teachers because of their lack of empathy or sympathy. This was especially felt among girls when they were sexually harassed by boys. As another female Standard 7 student explained, "Sometimes you can report something to the teacher and he or she thinks you are joking and speaks ill to you." Other female students explained that teachers often suggested that girls "invited" such harassment. In the words of a Standard 8 student, if she were to report unwanted sexual touching to a teacher, she would expect the following response, " ... that maybe I was playing bad games with the boys and that's why they touched me." In such cases, not only is the vulnerability of students exacerbated by a teacher's refusal to intervene, but a boy's violence is implicitly tolerated by a teacher's inclination to blame the girl.

A further complication related to student reports of violence was a frequent tendency of teachers to inflict corporal punishment on children deemed to be perpetrators of violence. This is depicted in Figure 3 which portrays students fighting and is accompanied by the words, "Teachers cane criminals." Besides having observed corporal punishment on numerous occasions, I also heard numerous students describe teachers' violence, typified by the following exchange:

Researcher: What will happen if you report to the teachers, what do you want them to do?

Student: Punish him.

Researcher: How?

Student: Wash [clean up] the class alone.

Researcher: And is that what happened?

Student: No ... He was being caned with a stick.

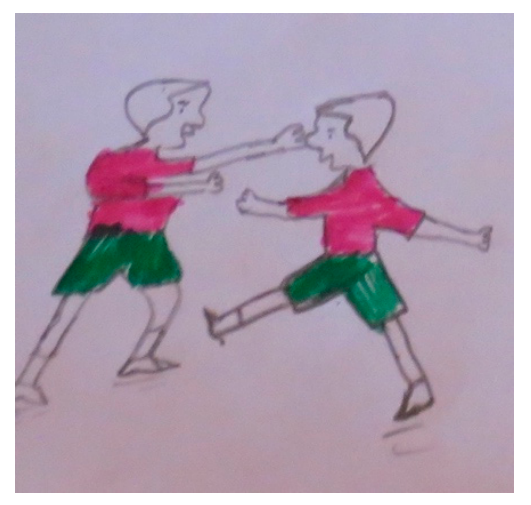

Figure 3. Teachers cane criminals. Student drawing. 
The generally accepted use of corporal punishment in both schools clearly contradicted the country's legal and policy regulations. As this study revealed, while some teachers proactively advocated for gender safety in the two schools, others exercised and reinforced various forms of gender violence, indicating the existence of competing gender narratives.

\section{Discussion}

The gender safety in schools (GSS) framework stipulates that a gender safe school: (1) is void of all forms of physical, sexual, psychological and emotional violence; (2) prioritizes gender equality in all academic and extra-curricular activities; (3) explicitly recognizes the existence of gender discrimination within society; and (4) actively challenges discriminatory gender practices, norms, and expectations that create unequal opportunities and unsafe spaces for girls and boys. Results from the two case study schools that aligned with this definition included equally high academic expectations for girls and boys, and in some instances teachers' efforts to safeguard children and to challenge unequal gender practices. Ultimately, however, neither school fit within the GSS framework as all major forms of gender violence (sexual harassment, corporal punishment, and bullying) were present to some degree in both schools. School administrators and most teachers did not recognize ongoing gender discrimination in extra-curricular activities, and they were generally reluctant to take actions beyond their own personal interventions.

Teachers' actions to support gender safety were largely enacted in a passive way; they rarely overtly challenged existing structures of gender inequality and gender violence within the school. When teachers did challenge the status quo, it was out of a sense of personal responsibility and in opposition to the hierarchical school system, not as an expectation of their employment. Despite some teachers' individual resistance, the authority of the school ultimately constrained teachers' ability to protect students from gender violence and discrimination, particularly in reference to reporting cases of sexual violence. In effect, just as education cannot be considered inclusive, equitable, or of good quality when students are vulnerable to norms and structures of violence, neither can GSS be attained if teachers are constrained by structures of authority that are impervious to change. A more systematic approach to ensuring girls' and boys' security and equality in school is needed, one that enhances the power of teachers to bring about the structural changes that many of them do implicitly understand are necessary. The use of the GSS framework here shows that to provide equal protection and empowerment for female and male students, teachers themselves must first be fully empowered to promote gender safety in and through schools.

In the two case study schools, support for teachers' actions to promote gender equality and protect students from gender violence was identified as a critical opportunity for enhancing GSS. There are initiatives in Kenya that seek to strengthen teachers' work in this respect. The Kenya Teacher Service Commission Beacon Teachers initiative is one example that uses a networked approach. By providing initial teacher training in child protection, it subsequently recruits the most engaged teachers to become Beacon Teachers who champion child protection in their schools and communities. Led mainly by women at the national level, and primarily funded by international Non-Government Organizations (NGOs), Beacon Teachers consists of trained female and male teachers who communicate via WhatsApp in order to encourage each other and maintain support from the Teacher Service Commission in their efforts to advocate for the protection of children in schools. This blending of new technology with a traditional approach to grass roots empowerment aims to mobilize teachers towards more proactive measures that will ensure gender safety in schools and, where necessary, challenge school authorities and the patriarchal norms that help to perpetuate gender violence in schools. Although not yet evaluated so as to assess its efficacy in enhancing GSS, the Beacon Teachers program nonetheless embodies a promising initiative that is designed to provide structural reinforcement for the natural inclination of many teachers to protect students in schools. The long-term aim is to foster a strong professional ethos that integrates GSS as a normative feature of school life, and the corresponding eradication of gender violence. This study also indicates, however, that teacher support alone will 
not substantively contribute to enhancing GSS without changes to the systems that constrain teacher agency. This analysis indicates a significant need for greater government vigilance in enacting its policy pronouncements in relation to gender equality and child protection and, where necessary, disciplining teachers and administrators who flagrantly violate child protection legislation. In recent years, there have been movements in this direction. For example, the government has dismissed hundreds of teachers found guilty of having sexually assaulted students $[39,40]$. Further efforts that need to be reinforced may include repercussions for teachers and administrators who fail to report or otherwise challenge child abuse and discrimination, and conversely formally recognizing those who take a stand against gender violence in schools and communities.

GSS can operate as a framework not only for policy and analysis, but also as the basis of a multi-sectoral, multi-level strategy for action that addresses systemic and structural intersections between gender, violence and poverty [13]. This is in line with Kenya's policy framework, and the guidance for creating gender-responsive education sector plans established by the GPE and UNGEI [10], but contrasts with approaches that are commonly used by international NGOs to promote school safety and gender equality at the school level through surface level initiatives such as extracurricular clubs or short-term teacher training. Generally undertaken as small-scale initiatives without consideration of the larger education systems within which they are embedded, or of the interactions between education systems and other institutions and sectors of society, these are unlikely to be effective or sustainable. A GSS framework that analyzes school-level opportunities and barriers to action necessitates attention to the cross-systemic connections between governing bodies not just of education, but as well of child welfare, health, police services and the judiciary, all of which are instrumental in ensuring safe learning environments for children. Within the education sector itself, the framework recognizes the interconnectedness of school policies, curricula, teacher education, pedagogy, classroom management approaches and student assessment. In contrast to conventional approaches typified by top-down policy formulation that so often do not translate into implementation at school and community levels, the GSS framework is a form of participatory, ground-up policy-making, involving teachers and students as stakeholders whose voices are sought and heeded. In so doing, its aim is to address the 'missing middle' of systemic interventions that are essential if national policies pertaining to gender safety in school are to be fully realized [5,41].

\section{Conclusions}

The SDGs emphasize country ownership of development agendas, a commitment to reaching the most vulnerable sectors of society, and interconnectedness across social sectors such as health, education, and child protection-all priorities that conceivably can contribute to the realization of gender safe schools. However, as this study has shown, policy rhetoric is unlikely to lead to change in school-level practices without a multi-level systemic prioritization of gender equality and child protection in education. The GSS framework provides a mechanism for analysis that identifies promising practices in schools, as well as barriers that perpetuate gender violence and discrimination. GSS is an essentially inter-sectoral approach that must be rooted in a thorough gender analysis of education, and corresponding cooperation of key social services, especially those in the child protection and education sectors. Despite the inclusion of the principle of equity in SDG 4, the broad nature of the goal means it encompasses many elements that may compete for funding and political will. It remains to be seen if national governments and international organizations will in fact channel the necessary resources to effectively support national systems in the directions required for education to effectively contribute to the transformation of oppressive gender norms. If efforts are undertaken to incorporate a GSS framework into ongoing monitoring and assessment of SDG 4, they may not only help to advance gender safety and equality principles in policy documents, curriculum, teacher education, and student assessment, but they may also serve as an ongoing reminder to monitor and support school administrators and teachers in enacting gender safety in everyday school life. 
Funding: This research was funded by the Social Sciences and Humanities Research Council of Canada (Joseph Armand Bombardier Canada Graduate Scholarship and Michael Smith Foreign Study Supplement).

Acknowledgments: I gratefully acknowledge the support and assistance of Octavian Gakuru and Mary Nyambura Kimani during fieldwork for this study, and Awad Ibrahim, Christabelle Sethna, Lorna McLean, and Elaine Unterhalter for their guidance. I likewise wish to thank Richard Maclure for his editorial assistance on this article. Finally, I recognize the financial support of the Social Sciences and Humanities Research Council of Canada that made this research possible.

Conflicts of Interest: I declare no conflict of interest. The funders had no role in the design of the study; in the collection, analyses, or interpretation of data; in the writing of the manuscript, or in the decision to publish the results.

\section{References}

1. United Nations. Sustainable Development Knowledge Platform. Available online: https:// sustainabledevelopment.un.org/sdg4 (accessed on 26 October 2018).

2. Eck, M.; Naidoo, J.; Sachs-Israel, M. The New Global Education Agenda: Education 2030: Developing the New Education agenda: An Inclusive, Comprehensive and Country-owned Process. Available online: https: / www-tandfonline-com.proxy3.library.mcgill.ca/doi/pdf/10.1080/03057925.2017.1339263 (accessed on 12 November 2018).

3. Aikman, S.; Unterhalter, E. Beyond Access: Transforming Policy and Practice; Oxfam: Oxford, UK, 2005.

4. Parkes, J.; Heslop, J.; Johnson Ross, F.; Westerveld, R.; Unterhalter, E. A Rigorous Review of Global Research Evidence on Policy and Practice on School-Related Gender-Based Violence; UNICEF: New York, NY, USA, 2016.

5. Holt, M.K.; Finkelhor, D.; Kantor, G.K. Multiple victimization experiences of urban elementary school students: Associations with psychosocial functioning and academic performance. Child Abus. Negl. 2007, 31, 503-515. [CrossRef] [PubMed]

6. Abuya, B.; Onsomu, E.; Moore, D.; Sagwe, J. A phenomenonological study of sexual harassment and violence among girls attending high schools in urban slums, Nairobi, Kenya. J. Sch. Violence 2012, 11, 323-344. [CrossRef]

7. Stromquist, N.P. Gender, education and the possibility of transformative knowledge. Compare 2006, 36, 145-161. [CrossRef]

8. Stein, N.; Tolman, D.L.; Porche, M.V.; Spencer, R. Gender safety: A new concept for safer and more equitable schools. J. Sch. Violence 2002, 1, 35-49. [CrossRef]

9. Mlama, P.; Dioum, M.; Makoye, H.; Murage, L.; Wagah, M.; Washika, R. Gender Responsive Pedagogy: A Teacher's Handbook; FAWE: Nairobi, Kenya, 2005.

10. Global Partnership for Education; United Nations Girls Education Initiative. Guidance for Developing Gender-Responsive Education Sector Plans; GPE \& UNGEI: Washington, DC, USA; New York, NY, USA, 2017.

11. Leach, F. Learning to be violent: The role of the school in developing adolescent gendered behaviour. Compare 2003, 3, 37-41. [CrossRef]

12. Leach, F.; Humphreys, S. Gender violence in schools: Taking the 'girls as victims' discourse forward. Gend. Dev. 2007, 15, 51-65. [CrossRef]

13. Parkes, J. Gender Violence in Poverty Contexts: The Educational Challenge; Routledge: Abingdon, UK, 2015.

14. Dunne, M.; Humphreys, S.; Leach, F. Gender violence in schools in the developing world. Gend. Educ. 2006, 18, 75-98. [CrossRef]

15. Humphreys, S. Gendering corporal punishment: Beyond the discourse of human rights. Gend. Educ. 2008, 20, 527-540. [CrossRef]

16. UNICEF. Violence Against Children in Kenya-Findings from a 2010 National Survey; United Nations Children's Fund Kenya Country Office: Nairobi, Kenya, 2012.

17. Chege, F. He put his hands between girls' thighs': Using student teachers' memories to tackle gender violence. In Combating Gender Violence in and Around Schools; Leach, F., Mitchell, C., Eds.; Trentham Books Ltd.: Stoke on Tent, UK, 2006; pp. 189-197.

18. Parkes, J.; Heslop, J.; Oando, S.; Sabaa, S.; Januario, F.; Figue, A. Conceptualising gender and violence in research: Insights from studies in schools and communities in Kenya, Ghana and Mozambique. Int. J. Educ. Dev. 2013, 33, 546-556. [CrossRef]

19. Ruto, S. Sexual abuse of school age children: Evidence from Kenya. J. Int. Coop. Educ. 2009, 12, 177-192. 
20. Wane, N. Sexual violence and HIV/AIDS risks in Kenyan and Ugandan schools: Social implications for educational policy development. J. Contemp. Issues Educ. 2009, 4, 71-91. [CrossRef]

21. Vanner, C. 'This is a competition': The relationship between examination pressure and gender violence in primary schools in Kenya. Int. J. Educ. Dev. 2018, 62, 35-46. [CrossRef]

22. Saito, M. Violence in primary schools in Southern and Eastern Africa: Some evidence from SACMEQ. SACMEQ Gend. Ser. 2013, 1, 1-3.

23. Republic of Kenya. Children Act; National Legislative Authorities, Government Printer: Nairobi, Kenya, 2014.

24. Republic of Kenya. Basic Education Act; Government Printer, Kenya Gazette Supplement: Nairobi, Kenya, 2012.

25. Republic of Kenya. Gender Policy in Education; Ministry of Education Science and Technology: Nairobi, Kenya, 2007.

26. Wango, G.; Mysomi, M.; Akinyi, C. Gender and education in Kenya and re-alignment of education to the constitution. In ITP Human Rights Towards Gender Equality Seminar; International Training Program: Nairobi, Kenya, 2012.

27. Republic of Kenya. Safety Standards Manual for Schools in Kenya: Schools as Safe Zones; Ministry of Education Science and Technology: Nairobi, Kenya, 2008.

28. Unterhalter, E.; North, A.; Arnot, M.; Lloyd, C.; Moletsane, L.; Murphy-Graham, E.; Saito, M. Interventions to Enhance Girls' Education and Gender Equality; DFID: London, UK, 2014.

29. Open Data. Kirinyaga County Data Sheet. Available online: https://opendata.go.ke/facet/counties/ Kirinyaga?utf8=\$\{ $\backslash$ mathchar"1270\}\$\&age=7 (accessed on 14 May 2014).

30. Kenya Information Guide. Overview of Kirinyaga County. Available online: http://www.kenyainformation-guide.com/kirinyaga-county.html (accessed on 26 March 2017).

31. Kenya National Bureau of Statistics. Exploring Kenya's Inequality: Pulling Apart or Pooling Together? Available online: http:/ / www.knbs.or.ke/index.php?option=com_phocadownload\&view=category\&id= 114:exploring-kenya-s-inequality\&Itemid=599 (accessed on 26 March 2017).

32. Mugo, J.; Kaburu, A.L.; Kimutai, A. Are Our Children Learning? Uwezo: Nairobi, Kenya, 2011.

33. Angrosino, M.; Rosenberg, J. Observations on observation: Continuities and change. In The SAGE Handbook of Qualitative Research, 4th ed.; Denzin, N., Lincoln, Y., Eds.; SAGE Publications: Thousand Oaks, CA, USA, 2011; pp. 467-478.

34. Ogina, T.A.; Nieuwenhuis, J. Gaining access to the experiences of orphaned children: A draw-write-narrate approach. Qual. Res. J. 2010, 10, 51-64. [CrossRef]

35. Vanner, C. 'The Gateway to Everything': The Relationship Between Gender Safety, Gender Violence and Learning Processes in Two Primary Schools in Kirinyaga County, Kenya. Ph.D. Thesis, University of Ottawa, Ottawa, ON, Canada, October 2017.

36. Charmaz, K. Constructing Grounded Theory; SAGE Publications: Thousand Oaks, CA, USA, 2006.

37. Koelsch, L.E. Reconceptualizing the member check interview. Int. J. Qual. Methods 2013, 12, 168-179. [CrossRef]

38. Teacher Service Commission. Protection of pupils/students from sexual abuse. TSC Circ. $2010,3$. Available online: https:/ / www.tsc.go.ke/index.php/media-centre/downloads/category/98-current-circulars? download=482: circular-on-protection-of-pupils-students-from-sexual-abuse-2010 (accessed on 19 March 2019).

39. Ochieng, D. TSC Delists 126 Teachers Over Sex Scandals and Misconduct. Daily Nation. Available online: http: / / www.nation.co.ke/news/TSC-blacklists-126-teachers/-/1056/2745682/-/isfj53z/- /index. html (accessed on 8 January 2016).

40. Wanzala, O. 96 Teachers Banned from Class for Life for Sex with Students. Available online: http://www. nation.co.ke/news/Teachers-Banned-TSC-Sex-Misconduct/-/1056/2746550/- /lw72tv/- /index.html (accessed on 26 October 2018).

41. Mitchell, C.; De Lange, N. Interventions that address sexual violence against girls and young women: Mapping the issues. Agenda 2015, 29, 3-12. [CrossRef]

(C) 2019 by the author. Licensee MDPI, Basel, Switzerland. This article is an open access article distributed under the terms and conditions of the Creative Commons Attribution (CC BY) license (http:/ / creativecommons.org/licenses/by/4.0/). 